\title{
O papel do inglês na formação e na internacionalização da educação no Brasil
}

\author{
Kyria Rebeca Finardi \\ Universidade Federal do Espírito Santo \\ kyria.finardi@gmail.com \\ Maria Carolina Porcino \\ Universidade Federal do Espírito Santo \\ carolina_porcino@hotmail.com
}

\section{Resumo}

O objetivo deste artigo é refletir acerca do papel do inglês na educação brasileira contemporânea. O estudo revisa políticas linguísticas e de internacionalização sugerindo que há uma tensão entre o papel formador e o papel instrumental da língua inglesa na educação atual. A fim de subsidiar a reflexão proposta, o estudo analisa dados de dois questionários com perguntas relacionadas ao ensino e à aprendizagem de línguas estrangeiras no Brasil. Utilizou-se uma metodologia híbrida analisando dados quantitativos e qualitativos dos questionários respondidos por 65 participantes, sendo 43 estudantes do ensino médio de uma comunidade capixaba de imigrantes pomeranos e 22 professores de inglês. A análise dos questionários sugere que os brasileiros querem aprender inglês como língua estrangeira e veem esse idioma como tendo status de língua internacional. Os resultados mostram que a maior diferença entre o ensino desse idioma no Brasil está nos seus papeis ora formador (na educação básica) ora instrumental (nos cursos livres e programas de internacionalização), confirmando a hipótese levantada na análise das políticas linguísticas de que há uma tensão entre os papeis formador e instrumental do inglês na educação brasileira.

Palavras-chave: Formação. Internacionalização. Educação. Papel do inglês.

\section{Abstract}

This paper aims at reflecting on the role of English in contemporary Brazilian education. The study reviews language and internationalization policies suggesting that there is a tension between the formative role and the 
instrumental role of English in education today. In order to subsidize the proposed reflection, the study analyzes data from two questionnaires with questions related to teaching and learning foreign languages in Brazil. A hybrid methodology was used to analyze quantitative and qualitative data from the questionnaires answered by 65 participants of whom 43 were high school students from a community with Pomeranian immigrants and 22 were English teachers. The analysis of the questionnaires suggests that Brazilians want to learn English as a foreign language and see that language as having the status of an international language. Results show that the main difference between the teaching of this language in Brazil is related to its formative role (in basic education) and its instrumental role (in private language institutes and international programs), confirming the hypothesis raised in the analysis of language policies that there is a tension between the formative and instrumental roles of English in Brazilian education.

Keywords: Formation. Internationalization. Education. Role of English.

\section{Introdução}

Ao contrário do que muitos brasileiros pensam, o Brasil é um país multilíngue, com dezenas de imigrantes, índios e surdos que não têm o português como língua materna. Como apontado por Leffa (2013), é preciso lutar contra a indiferença, a omissão e a discriminação dessas minorias linguísticas por meio da reflexão e da elaboração de políticas linguísticas que promovam o entendimento e a tolerância na convivência entre falantes de variadas línguas, sejam elas minoritárias ou simplesmente línguas majoritárias carregadas de preconceito ou associadas a possíveis perigos ideológicos, como é o caso do inglês.

Cientes da difícil, mas não menos importante tarefa de pensar as políticas linguísticas, a Alab, ${ }^{1}$ por ocasião de seu último encontro nacional, ${ }^{2}$ convidou linguistas aplicados de todo o Brasil a refletirem sobre seu papel e o papel das línguas, sejam

\footnotetext{
${ }^{1}$ Associação Brasileira de Linguística Aplicada.

${ }^{2}$ X Congresso Brasileiro de Linguística Aplicada realizado em setembro de 2013 na UFRJ.
} 
elas maternas sejam adicionais $^{3}$ (doravante LA) no atual momento histórico. Este trabalho constitui um aceite a esse convite e representa uma contribuição por meio da reflexão sobre o papel do inglês no atual contexto da educação brasileira em diferentes níveis.

Segundo Rajagopalan (2013, p. 21): "Política linguística é a arte de conduzir as reflexões em torno de línguas específicas com o intuito de conduzir ações concretas de interesse público relativo à(s) língua(s) que importam para o povo de uma nação, de um estado ou, ainda, instâncias transnacionais maiores". Concordarmos com Lagares (2013, p. 185) e Rajagopalan (2006) que o ensino de línguas adicionais é, claramente, uma questão política, uma vez que aspectos metodológicos que incidem diretamente na abordagem das línguas dentro da sala de aula decorrem de decisões tomadas alhures. A própria decisão sobre as línguas adicionais que integram o currículo escolar é consequência de debates sociais e medidas legislativas que surgem em contextos geopolíticos e econômicos concretos.

Conforme nos lembra Lagares (2013, p. 185), o ensino de línguas adicionais no Brasil foi por vezes tratado como componente extracurricular, passando até por um processo de terceirização no qual a língua adicional tinha uma função instrumental no sentido de capacitar brasileiros a usarem essa

3 Adotamos o termo língua adicional no lugar de língua estrangeira por entender que o termo língua adicional se adequa melhor ao que pensamos que deva ser o ensino de uma língua que não a materna, por se encaixar nas novas tendências de uma linguística aplicada crítica que entende o usuário da língua não como um estranho à língua. Nesse sentido, entende-se o usuário da língua como alguém que, por opção ou exposição, aprende uma língua ou mais, além da sua materna, não denotando uma língua como inferior à outra, ou de valor simbólico diferente. $\mathrm{O}$ termo estrangeira, ao contrário, parece sugerir que a língua seja estranha ou exótica, com conotações indesejáveis. Nossa opção pelo termo adicional alinha-se à nossa crença de que as línguas adicionais não são inferiores, superiores ou mesmo substitutivas da primeira língua (NICOLAIDES; TILIO, 2013, p. 285).

Horizontes de Linguística Aplicada, ano 14, n. 1, 2015 
língua para comunicação ou acesso à informação em geral, baseada na crença comum de que a escola não é lugar para aprender línguas adicionais (p. 186). Essa noção de que não se aprende inglês na escola é questionada por autores (TILIO, no prelo, apud NICOLAIDES; TILIO, 2013, p. 294) que sugerem que assim como a escola não forma matemáticos, historiadores e físicos, para dar apenas alguns exemplos, ela não deveria ter a responsabilidade de formar falantes fluentes em línguas estrangeiras. Gimenez (2009 apud MACIEL, 2013, p. 238) afirma que há dois mundos paralelos: o dos documentos oficiais e o da sala de aula, mas seja qual for o papel que entendemos ser o da escola, a prática da sala de aula não pode continuar alheia aos documentos oficiais e às políticas linguísticas, uma vez que estas têm implicações sobre a sala de aula, a escolha do material didático e as estratégias de ensino utilizadas (LAGARES, 2013, p. 190). Assim, é preciso pensar nas políticas linguísticas em todos os âmbitos, e é nesse sentido que este trabalho oferece uma contribuição ao dar voz a todos os envolvidos no processo de ensino aprendizagem de inglês como LA: alunos, professores de cursos livres (os "terceirizados"), professores educadores e formadores e linguistas aplicados.

Sem negar a importância dessas vozes, bem como daquelas advindas da educação e da linguística aplicada, é preciso não esquecer o alerta de Rajagopalan (2006) de que o ensino de línguas deve ater-se às demandas impostas pelas relações políticas nas quais se encontra o país, tanto no âmbito interno quanto na esfera externa (RAJAGOPALAN, 2006, p. 22 apud LAGARES, 2013, p. 197). Nesse sentido, este artigo reflete sobre as possíveis implicações de ensinar (ou não) inglês como língua adicional (formadora ou funcional) no atual contexto geopolítico brasileiro. Entendemos que o papel formador da língua adicional se relaciona com o desenvolvimento da capacidade do indivíduo de ver e entender o outro por meio de outra língua e cultura, enquanto o papel instrumental ou 
funcional da língua adicional está mais relacionado ao desenvolvimento da capacidade do indivíduo de usar essa língua para se comunicar, acessando e produzindo informação nesta. Para tanto, fazemos uma breve contextualização do cenário da educação do inglês no Brasil contemporâneo.

Segundo relata Gimenez (2013 p. 202), um levantamento realizado pela empresa English First mostrou que o desempenho dos brasileiros em inglês está no $46^{\circ}$ lugar num ranking de 54 países. $O$ Globo noticiou em 30/09/2012: "Brasileiros não sabem falar inglês: apenas 5\% dominam o idioma". Apesar dessas estatísticas, parece haver um sentimento generalizado (e comprovado pelos dados trazidos neste estudo) de que os brasileiros querem aprender e falar inglês. Gimenez (2013) sugere que há uma valorização do aprendizado de inglês no Brasil ao reconhecer o conhecimento da língua inglesa como essencial para a participação no mundo globalizado no qual ela exerce o papel de língua franca, conforme demonstrado exemplarmente pela declaração da escritora Lilian Carmine na Folha de São Paulo: "Escrevi em inglês para ser lida" (GIMENEZ et al., 2011 apud GIMENEZ, 2013, p. 203). Seguindo o mesmo raciocínio da escritora, escrevemos agora em português para "sermos ouvidas".

Como veremos neste estudo, independentemente das políticas linguísticas ou dos sentimentos antagônicos em relação à possível hegemonia do inglês, "ameaçando" outras línguas estrangeiras (para não falar das minoritárias) e identidades, os brasileiros querem aprender inglês. Ora, se esse desejo é real e se concretiza no sucesso (ou fracasso) das políticas de internacionalização, ${ }^{4}$ por que não está presente nas políticas

${ }^{4}$ Vide o programa Ciência sem Fronteiras $(\mathrm{CsF})$, cujo sucesso (ou fracasso) pode ser atribuído ao nível de proficiência em inglês dos possíveis candidatos, conforme atestam programas lançados posteriormente, como o Inglês sem Fronteiras (IsF), para suprir essa lacuna na ensinagem de inglês aos candidatos ao CsF.

Horizontes de Linguística Aplicada, ano 14, n. 1, 2015 
linguísticas praticadas na atualidade? Lembramos que a ausência de políticas alinhadas ao desejo popular pode acarretar sérias consequências sociais, como temos presenciado nos vários protestos ocorridos em todo o país desde $2013 .{ }^{5}$ Uma dessas consequências no caso da ausência de políticas linguísticas para a internacionalização e o ensino de inglês como língua internacional ${ }^{6}$ no Brasil é a desigualdade de oferta de cursos de inglês, favorecendo o ensino no setor privado, o que aumenta assim a desigualdade social por meio da terceirização da oferta de cursos livres de inglês que efetivamente formem falantes fluentes e proficientes do idioma. Outra consequência da falta de políticas linguísticas e de internacionalização que reconheçam o papel do inglês no cenário atual é a indesejável dissociação dos papéis da língua inglesa, ora sendo vista como formadora na educação básica, ora como tendo um papel instrumental nos cursos livres e nos programas de internacionalização. Os dados trazidos neste estudo apontam exatamente para essa dicotomia do papel do inglês no Brasil.

Considerando-se as políticas de ensino de línguas adicionais no Brasil no momento em que se propõem programas de internacionalização, como o Ciência sem Fronteiras e o Inglês sem Fronteiras, é preciso ampliar o debate com vistas a propor políticas que considerem uma visão de educação condizente com os desafios da sociedade atual, reconhecendo a necessidade de mais investimento no profissionalismo docente, preparando professores para as devidas mediações entre linguagens,

\footnotetext{
${ }^{5}$ Protestos iniciados em várias regiões do Brasil em junho de 2013 com o Movimento Passe Livre.

${ }^{6}$ Entendemos que uma língua internacional é aquela usada em contextos nacionais, internacionais e transnacionais por usuários nativos e não nativos que aprendem e usam esse idioma como língua internacional não associada a uma cultura específica. Para uma revisão completa dos termos língua internacional, adicional, estrangeira e franca ver Jordão (2014). 
tecnologias e os contextos locais e globais (MONTE MÒR, 2013, p. 233).

Sobre as mediações da tecnologia e do contexto local e global bem como sobre o papel do inglês no mundo globalizado, Graddol (2006) e Finardi, Prebianca e Momm (2013) sugerem que o inglês e a tecnologia ampliam o acesso à informação e consequentemente a participação do indivíduo na era do conhecimento. Essa visão não é, contudo, livre de ataques. De acordo com Omoniyi e Saxena (2010, p. 214, apud MACIEL, 2013, p. 253), a visão do ensino de inglês como progresso está ligada à noção de globalização. Que, por sua vez, está associada a uma tendência progressista que se encontra no cerne da agenda capitalista e associa a globalização à expansão de mercado e ao fortalecimento da democracia ocidental. Segundo Rojo (2013, p. 74), a globalização é regida por três dicotomias, a saber: a local/global, a do Estado-nação/não Estado transnacional e a do capitalismo/lutas anticapitalistas. Nesse cenário, saber inglês estaria ligado à possibilidade de se ter as portas do mundo abertas e reflete o que Lankshear (2007, p. 317 apud MACIEL, 2013, p. 253) chama de a concepção neoliberal sobre pessoas e sociedade em que a educação valoriza a "individualização e a comodificação de língua e letramento".

Ainda sobre os supostos perigos da comodificação de língua e letramento ou do ensino de inglês instrumental nessa visão de globalização, Canagarajah (2013) sugere que o ensino de inglês como instrumento neutro ou apolítico (value-free nas palavras da autora, p. 44) para alcançar progresso perpetua a dominação global dos países anglo-falantes (CANAGARAJAH, 2013 , p. 47), uma vez que não permite a negociação de identidades locais e globais (p. 57). Ousamos discordar da autora por entender que um perigo maior reside na falta de ensino de inglês, seja ele político ou não, instrumental ou não, no atual contexto global, na medida em que essa falta aumenta a lacuna entre os que têm acesso à informação global (e, por conseguinte, 
podem exercer suas cidadanias no mundo globalizado) e os que não têm. Assim, propomos que a solução dessas contradições da globalização no que diz respeito ao ensino de inglês no Brasil não está no ensino (ou não) de inglês (ou de outra língua estrangeira), mas sim no ensino crítico de inglês como língua adicional e internacional, que pressupõe o reconhecimento do seu papel formador e instrumental, global e local no cenário contemporâneo. Assim, revisamos em seguida algumas políticas linguísticas e um programa de internacionalização a fim de refletir sobre possibilidades desse ensino crítico de inglês como língua internacional na atual conjuntura nacional.

A Resolução CNE/CEB 7/2010, que fixa diretrizes curriculares nacionais para o ensino fundamental, estabelece em seu artigo 15 que a língua estrangeira moderna é componente curricular obrigatório, e em seu artigo 17 prevê que na parte diversificada do currículo do ensino fundamental será incluído, obrigatoriamente, a partir do $6^{\circ}$ ano (ou $5^{\frac{\mathrm{a}}{}}$ série) o ensino de, pelo menos, uma língua estrangeira moderna, cuja escolha ficará a cargo da comunidade escolar. Entretanto, em seu parágrafo único a resolução prevê que entre as línguas estrangeiras modernas a língua espanhola poderá ser a opção, nos termos da Lei $\mathrm{n}^{\mathrm{o}} 11.161 / 2005$.

Seja qual for o motivo para essa menção explícita ao espanhol e apesar de não ferir a Lei de Diretrizes e Bases de 1996, que rege a educação brasileira, determinando que a escolha da língua estrangeira deva ser feita pela comunidade escolar, parece haver no parágrafo único da Resolução CNE/CEB 7/2010 uma sugestão explícita à escolha da língua espanhola. Conforme sugere Gimenez (2013, p. 208), duas possibilidades decorrem dessa sugestão explícita: ou se prevê que o ensino de espanhol deva acontecer como parte de um projeto maior da sociedade brasileira (que careceria, a nosso ver, de uma explicação sobre o 
projeto) ou se busca apenas não desagradar alguns setores. ${ }^{7}$ Seja qual for a justificativa para o parágrafo único da resolução supracitada, fica patente a ambiguidade subjacente a políticas de ensino de línguas estrangeiras no Brasil, que ora veem seu ensino como parte do componente fundamental de formação, ora fazendo parte do núcleo comum, ora integrando a parte diversificada do currículo; ora sendo ofertada de acordo com a escolha da comunidade escolar, ora sendo a língua espanhola, ora sendo a língua inglesa. Entretanto, e como ainda nos lembra Gimenez (2013, p. 208), "correndo por fora" e fortalecida pela globalização econômica está a língua inglesa, cujo caráter distintivo em relação às demais línguas se torna visível no programa Inglês sem Fronteiras e na política de internacionalização que o Brasil adota, um pouco tardia e desorganizadamente por não se articular com políticas educacionais e linguísticas de base. Daí nossa intenção de analisar as políticas desde a base até o topo, sugerindo como o papel do inglês pode ser entendido nesse novo cenário.

Ainda sobre as políticas linguísticas, Monte Mór (2013, p. 230) explica que os estudos sobre letramentos (NEW LONDON GROUP, 1996; LANKSHEAR; KNOBLE, 2003; 2011; GEE, 2003, 2010; KRESS, 2000, 2010, apud MONTE MÓR, 2013) surgiram a partir da percepção de que as mudanças sociais, culturais e políticas advindas dos conhecimentos da tecnologia digital e do fenômeno da globalização exigiam um novo olhar sobre premissas educacionais até então praticadas, alinhando-se, a nosso ver, à previsão da educação do futuro esposada por Graddol (2006). Partindo dos estudos sobre letramentos são propostas as Orientações Curriculares para o Ensino Médio - OCEMs - Línguas Estrangeiras (BRASIL, 2006), que pretendem superar a visão de ensino tradicional de

\footnotetext{
${ }^{7}$ A fim de conhecer alguns desses possíveis interesses e setores, sugerimos a leitura de Lagares (2013) sobre o ensino de espanhol no Brasil.
} 
língua tendo em mente as necessidades do aluno brasileiro, que, de acordo com essa proposta, não precisa apropriar-se da língua inglesa padrão, respondendo a uma assimilação da cultura e da sociedade dos países anglo-falantes, conforme vemos no seguinte trecho da Ocem, também citado por Monte Mór (2013, p. 232).

As orientações curriculares para línguas estrangeiras têm como objetivo: retomar a reflexão sobre a função educacional do ensino de línguas estrangeiras no ensino médio e ressaltar a importância destas; reafirmar a relevância da noção de cidadania para discutir a prática dessa noção no ensino de línguas estrangeiras; discutir o problema da exclusão no ensino em face de valores "globalizantes" $e$ o sentimento de inclusão frequentemente aliado ao conhecimento de Línguas Estrangeiras; introduzir as teorias sobre a linguagem e as novas tecnologias (letramentos, multiletramentos, multimodalidade, hipertexto) e dar sugestões sobre a prática do ensino de línguas estrangeiras por meio destas (BRASIL, 2006, p. 87).

Outra ambiguidade observada no tocante às políticas de ensino de inglês no Brasil reside na sugestão dos Parâmetros Curriculares Nacionais - PCN (BRASIL, 1998) de que o foco seja apenas em uma habilidade linguística, recomendando fortemente que essa habilidade seja a de leitura, quando, por sua vez, vemos nas Ocems (BRASIL, 2006) a sugestão de que sejam trabalhadas as habilidades de leitura, compreensão oral e prática escrita, enfatizando a importância de se trabalhar outras habilidades, como o letramento crítico, digital e a oralidade.

Do exposto até aqui em termos de políticas e orientações para o ensino de línguas estrangeiras desde o ensino fundamental até o médio no Brasil, podemos concluir que há mais de uma política linguística no tocante ao ensino de inglês: uma para o 
ensino fundamental e outra para o ensino médio, e como veremos mais adiante na revisão da política (ou falta de) internacionalização, há ainda outra política linguística para o ensino de inglês no ensino superior, demonstrando claramente a necessidade de pensarmos num alinhamento filosófico e educacional de políticas linguísticas no tocante ao ensino de inglês no Brasil contemporâneo.

À semelhança das resoluções e das orientações que compõem os documentos oficiais que regem o ensino de línguas no Brasil, outro tipo de política de ensino de línguas que também impacta a educação e a economia como um todo é a política, ainda um pouco desarticulada (NICOLAIDES; TILIO, 2013), de internacionalização do ensino superior. Finardi e Ortiz (2014) analisaram o processo de internacionalização do curso de Administração de duas universidades brasileiras, uma pública federal e a outra particular, mostrando que as universidades investigadas carecem de uma política de internacionalização articulada, limitando-se a programas de mobilidade acadêmica, a maior parte do tipo OUT, ${ }^{8}$ como o programa Ciência sem Fronteiras. $\mathrm{O}$ estudo conclui ainda que, a fim de promover a internacionalização do ensino superior, é necessário investir em programas de mobilidade acadêmica do tipo IN, cujo maior obstáculo é a barreira linguística, tendo em vista que nossas universidades não oferecem cursos de ou em inglês como componentes curriculares.

O principal programa de internacionalização do governo atual é o Ciência sem Fronteiras, que oferece, desde sua criação, 100 mil bolsas para universitários estudarem no exterior com o objetivo de desenvolver e expandir a educação superior, bem como a pesquisa científica e tecnológica por meio da

\footnotetext{
${ }^{8}$ Os programas de mobilidade acadêmica são divididos em mobilidade OUT, que enviam acadêmicos para o exterior, e os de mobilidade IN, cujo objetivo é incentivar a vinda de acadêmicos.
} 
internacionalização de nossas universidades. Esse programa esbarrou numa série de dificuldades na implementação dessas bolsas, tendo sido a mais séria delas a falta de proficiência em inglês dos candidatos.

O programa Inglês sem Fronteiras (IsF) foi criado em 2012 para sanar essa lacuna e representa um grande avanço no desenvolvimento da língua inglesa, sendo uma prova de reconhecimento pelo governo de que o inglês tem um papel diferenciado das outras línguas estrangeiras e que não é contemplado de forma satisfatória na educação básica, razão pela qual essa lacuna tem de ser "compensada" no ensino superior.

Por entendermos que vivemos um momento político e econômico propício a mudanças no contexto educacional, aceitamos a convocação de Nicolaides e Tilio (2013) para sair de nossa zona de conforto, onde nos limitamos a desenvolver nossas pesquisas, dar nossas aulas e fazer nosso trabalho sem confrontar crenças como "não se aprende inglês na escola"; "vivemos em um país monolíngue na prática, e isso nos impede de alcançar um maior destaque no mercado internacional em termos econômicos"; "nossos pesquisadores publicam pouco em inglês"; "políticas linguísticas são para tratar de questões referentes a direitos linguísticos de línguas de indígenas e de imigrantes, e isso pouco nos diz respeito" (NICOLAIDES; TILIO, 2013, p. 287), convidando a todos a se unirem a nós no sentido de pensar no médio e no longo prazos políticas linguísticas da base até o topo capazes de refletir a realidade e a necessidade da sociedade contemporânea, formando cidadãos críticos e reflexivos, capazes de exercer sua cidadania no mundo globalizado.

Este estudo representa uma tentativa de ampliar a discussão em torno do papel do inglês no Brasil, propondo uma reflexão com apoio na "escuta" das vozes de representantes de vários segmentos desde a base, com alunos do ensino médio, até o topo, com professores de inglês de cursos livres, professores de inglês como língua estrangeira de cursos regulares, licenciandos 
em Letras inglês e professores formadores do curso de Letras inglês. A seguir descrevemos a metodologia do estudo.

\section{Metodologia}

Canagarajah (2002; 2005; 2006 apud MACIEL, 2013, p.242) nos lembra que o empirismo inspirado pelo Iluminismo levou a uma crise do conhecimento local, colocando em primeiro plano o conhecimento global. Como forma de resgatar o conhecimento local, Maciel (2013, p. 243) sugere o desenvolvimento de pesquisa em formação de professores informada pela etnografia a fim de abrir espaço para legitimar o conhecimento local do professor no sentido de considerar suas experiências, de analisar o cotidiano da sala de aula, bem como de discutir os conflitos que podem emergir quando uma proposta institucional entra em contato com o conhecimento local.

Esta pesquisa não tem cunho estritamente etnográfico, pois não observou fenômenos in loco nem trata das experiências observadas e discutidas em profundidade por questões de espaço, mas tenta resgatar o conhecimento local utilizando a escuta das vozes de representantes de vários níveis, da base até o topo da educação de inglês no Brasil.

O estudo é de cunho híbrido (DORNYEI, 2007), uma vez que utiliza dados quantitativos e qualitativos para entender a visão desses representantes sobre o papel do inglês no Brasil. Dois instrumentos de coleta de dados foram elaborados para este estudo, realizado no ano de 2014: um questionário para alunos de inglês do ensino médio (Apêndice 1) de uma comunidade capixaba, onde há grande porcentagem de imigrantes pomeranos e se discute atualmente um projeto de lei para incluir esse idioma como língua estrangeira nas escolas, e outro para professores de inglês de diversos níveis (Apêndice 2) de uma capital e universidade federal do Sudeste. O objetivo do questionário era 
avaliar as crenças sobre o ensino de línguas estrangeiras em geral e do inglês especificamente no Brasil. A análise dos dados foi feita em duas partes: primeiro os questionários dos alunos e em seguida os questionários dos professores, por último foram contrastados os dois tipos. A técnica utilizada para a análise quantitativa foi a contagem de vezes que um determinado tópico foi mencionado nas respostas. Em relação à análise qualitativa, foi feita a interpretação das respostas e dos tópicos citados para a triangulação dos dados.

O questionário dos alunos continha três perguntas sobre o ensino de línguas estrangeiras no Brasil, as quais foram respondidas por 43 alunos do ensino médio de uma comunidade com grande número de imigrantes alemães que falam pomerano no Espírito Santo. As respostas foram transcritas para análise qualitativa. As respostas à pergunta número 1 foram agrupadas em um gráfico para facilitar a visualização e a análise quantitativa.

O questionário dos professores continha cinco perguntas e foi respondido por 22 professores de inglês assim distribuídos: quatro professores formadores do curso de Letras inglês, cinco professores de inglês como língua estrangeira e 13 licenciandos em Letras inglês. As respostas do questionário foram transcritas e tabuladas de acordo com a frequência de menção de temas comuns a fim de permitir a análise quantitativa e qualitativa.

\section{Análise dos resultados}

A primeira pergunta do questionário respondido pelos alunos do ensino médio da comunidade capixaba onde se discute o projeto de lei para incluir o pomerano como língua estrangeira nas escolas públicas pedia que os alunos marcassem, de 1 a 5 , qual idioma estrangeiro gostariam de aprender, sendo 1 o idioma que mais gostariam de aprender e 5 o que menos gostariam de 
aprender. Como se pode observar na Figura 1, o idioma mais desejado foi o inglês, seguido do espanhol. Apesar de grande número desses alunos ser filho de imigrantes pomeranos, poucos colocaram o pomerano como primeira ou segunda opção de língua estrangeira.

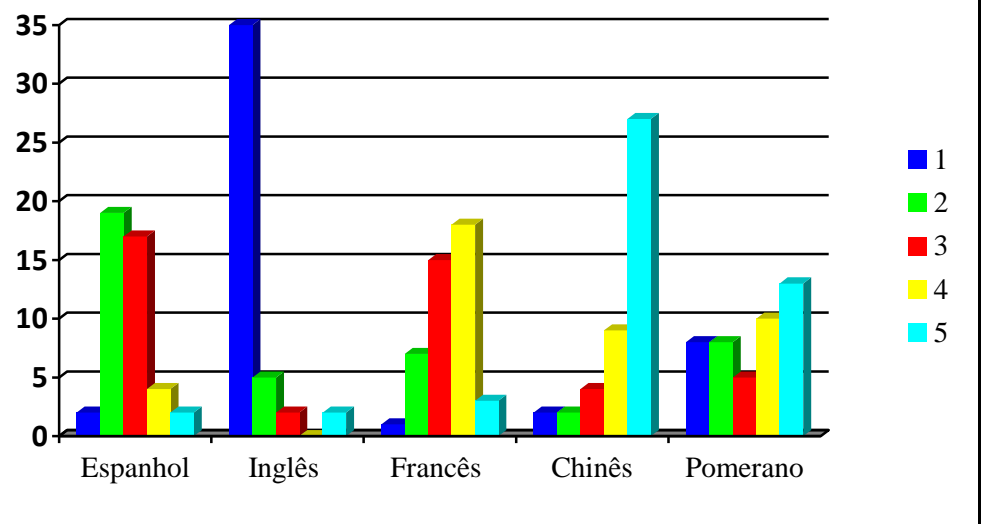

Figura 1: Respostas dos alunos do ensino médio sobre qual idioma gostariam de aprender. As cores representam a importância de 1 a 5 atribuída a cada idioma, sendo o número 1 o mais importante.

Fonte: Elaboração das autoras, adaptado de Peruzzo (2014).

A segunda pergunta do questionário respondido pelos alunos perguntava qual o idioma estrangeiro que eles gostariam de aprender se pudessem escolher apenas um, e novamente o inglês (com 33 dos 43 votos) foi o mais votado. Outro dado interessante é que pouquíssimos (apenas três de 43) alunos de ensino médio dessa comunidade escolheram o pomerano, rejeitando a hipótese levantada pelas pesquisadoras de que escolheriam esse idioma em razão de sua descendência e relevância para essa região. Dos dez alunos que responderam que gostariam de aprender outro idioma que não o inglês, quatro deles responderam que gostariam de aprender japonês, um 
respondeu que gostaria de aprender espanhol, um gostaria de aprender português de Portugal e um gostaria de aprender italiano. Os três únicos alunos que escolheram o pomerano disseram que seria interessante aprender esse idioma para falar com seus avós, mas acreditavam que o inglês dava mais condições de trabalho tanto dentro quanto fora da comunidade.

Com relação ao questionário respondido pelos professores, a primeira pergunta era por que deveríamos ensinar inglês (e não outra língua estrangeira) nas escolas no Brasil. Dentre os 22 professores respondentes, apenas um disse que não deveríamos ensinar inglês, e sim qualquer outra língua estrangeira que fosse relevante num determinado contexto. Dos outros 21 professores que responderam que deveríamos ensinar inglês como língua estrangeira no Brasil, a grande maioria justificou sua resposta dizendo que o inglês é o idioma internacional, usando diferentes termos para se referir ao status desse idioma, dentre eles: idioma universal, franco, internacional, transnacional, comercial, funcional e global. A análise das respostas foi feita tanto de forma quantitativa (número de vezes que um determinado termo era mencionado) quanto qualitativa, a fim de responder às cinco perguntas do questionário dos professores. Assim, é importante esclarecer que os números mencionados aqui não representam o número de professores que deram uma determinada resposta, mas sim o número de vezes que uma determinada resposta foi dada. Dentre os 21 professores que responderam afirmativamente à pergunta $\mathrm{n}^{\mathrm{o}}-1$ do questionário, eles ainda citaram outros motivos para o ensino de inglês no Brasil, sendo o fator de empoderamento ${ }^{9}$ da língua inglesa citado sete vezes, e o acesso à informação e publicação citado três vezes.

\footnotetext{
${ }^{9} \mathrm{O}$ fator de empoderamento está relacionado à possibilidade de acesso e exercício da cidadania global por meio de uma língua.
} 


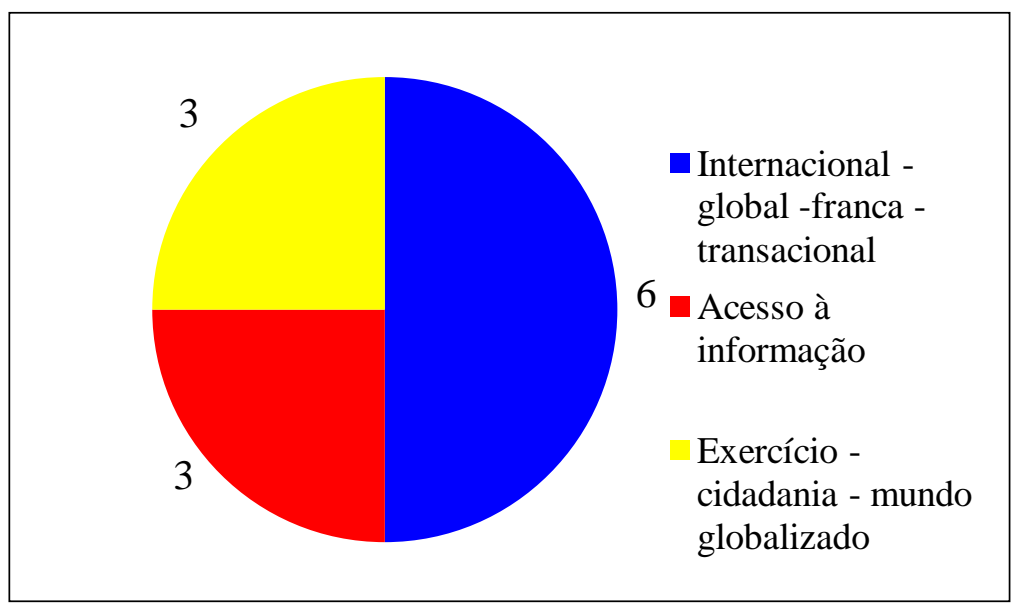

Figura 2: Respostas dos professores à pergunta "por que ensinar inglês (e não outra língua) no Brasil?".

Fonte: Elaboração das autoras (2014).

A segunda pergunta do questionário dos professores era que tipo de inglês deveríamos ensinar, e novamente a grande maioria (18 de 22) respondeu que deveríamos ensinar o inglês internacional, usando para isso algumas terminologias citadas na pergunta 1 acima (inglês como idioma franco, internacional, transnacional e global). Apenas um professor disse que deveríamos ensinar inglês americano ou britânico, e apenas um respondeu que deveríamos ensinar o nosso inglês, o inglês brasileiro. Dois professores responderam que deveríamos ensinar vários tipos de inglês, não focando em apenas uma variante. 


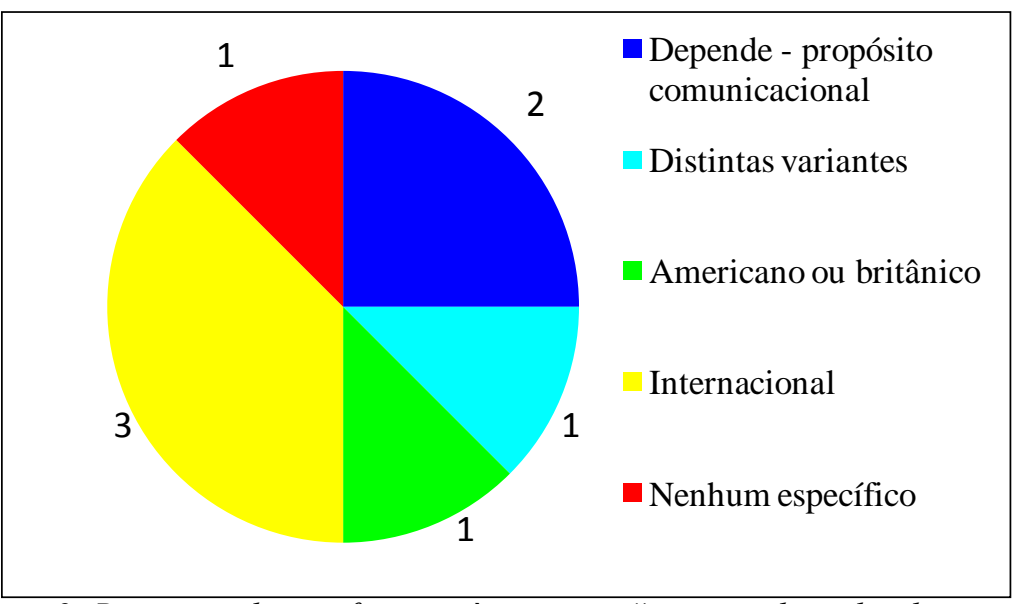

Figura 3: Respostas dos professores à pergunta "que tipo de inglês devemos ensinar?".

Fonte: Elaboração das autoras (2014).

A terceira pergunta do questionário dos professores era em qual das habilidades deveríamos focar, e a grande maioria (15 de 22) respondeu que deveríamos focar nas quatro habilidades. Dois professores disseram que deveríamos focar em todas as habilidades (incluindo pensamento crítico, tradução, para dar dois exemplos apenas), três professores disseram que deveríamos focar mais na oralidade, e dois professores responderam que deveríamos focar na escrita. 


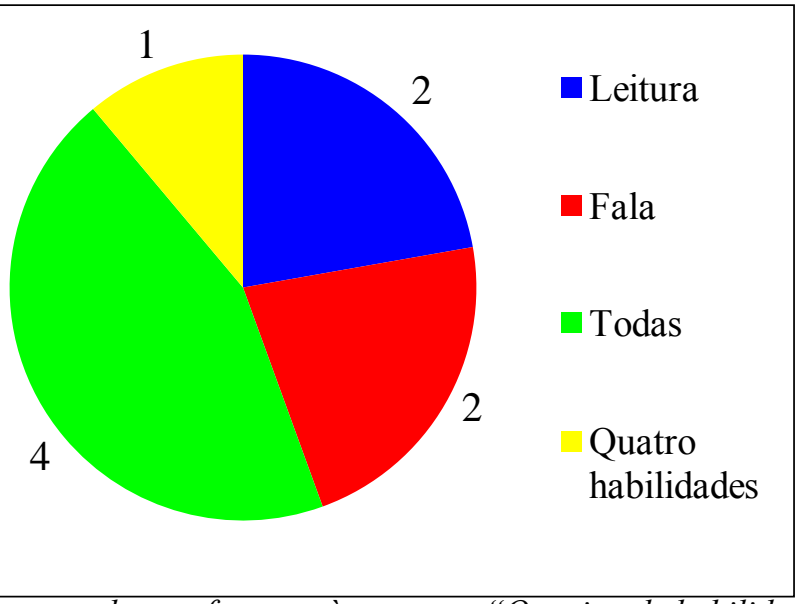

Figura 4: Respostas dos professores à pergunta "Que tipo de habilidade ensinar?".

Fonte: Elaboração das autoras (2014).

A quarta pergunta do questionário dos professores era se havia diferença entre o ensino de inglês nas escolas e nos cursinhos livres. Todos responderam afirmativamente a essa pergunta e qualificaram as diferenças entre os dois da seguinte forma: segundo eles, o ensino de inglês nas escolas é voltado para a formação de cidadãos (2) e tem turmas grandes, desniveladas e com foco na leitura (4); o ensino de inglês nos cursinhos livres é mais bem equipado (3), mais eficiente (2), voltado para o mercado (2) e tem turmas menores, com foco na oralidade (3). Podemos notar que, segundo os professores, o inglês tem um papel formador nas escolas e instrumental nos cursos livres. 


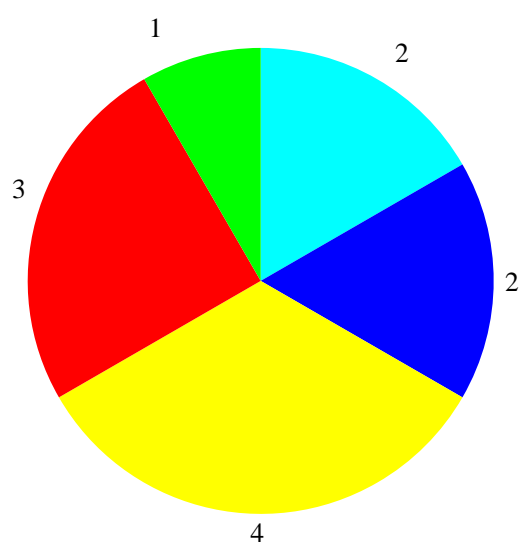

Carga horária reduzida (pública)

- Foco na leitura (pública)

Melhor equipado (privado)

Mais eficiente (privado)

Não há diferença

Figura 5: Respostas dos professores à pergunta "há diferença entre o ensino de inglês nas escolas e nos cursos livres?".

Fonte: Elaboração das autoras (2014).

Finalmente, a quinta pergunta do questionário era como deveríamos ensinar inglês no Brasil, e novamente a maioria dos professores respondeu que deveríamos ensinar de forma crítica, considerando o status da língua como idioma internacional. Um professor mencionou o fato de ensinarmos inglês de forma interdisciplinar, um como segunda língua, um como comunicação e um sugeriu que as turmas fossem niveladas por proficiência, como é nos cursos livres. 


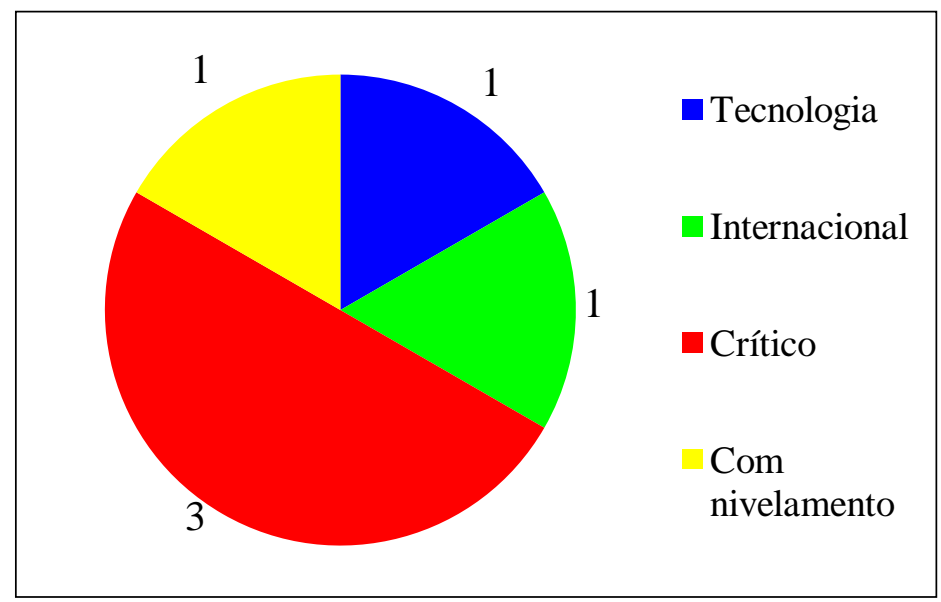

Figura 6: Respostas dos professores à pergunta "como deveríamos ensinar inglês no Brasil?".

Fonte: Elaboração das autoras (2014).

Das cinco perguntas feitas aos professores podemos resumir e concluir que: devemos ensinar inglês e não outra língua estrangeira por seu status de língua internacional, tentando diminuir a lacuna percebida entre o ensino desse idioma nas escolas e nas universidades, como ficou evidente na revisão de política linguística concretizada em programas de internacionalização, como o Inglês sem Fronteiras. Os professores parecem concordar que o ensino de inglês nos cursos livres é mais eficiente (foco na oralidade), enquanto o ensino de inglês nas escolas é mais voltado para o acesso à informação apenas (foco na leitura) e na formação do cidadão.

Podemos dizer que apesar do papel "formador" do ensino de inglês nas escolas e do papel "funcional" ou instrumental do ensino de inglês nos cursos livres, o ensino de inglês no Brasil carece de uma perspectiva crítica apoiada em políticas linguísticas que reconheça ambos os papéis por meio de orientações e reformas educacionais desde a base até o topo do Horizontes de Linguística Aplicada, ano 14, n. 1, 2015 
sistema educacional. Isso fica claro quando vemos programas como o Inglês sem Fronteiras suprindo a lacuna do papel instrumental não contemplado pela educação regular e pública na base. Quando contrastamos as visões dos professores com a dos alunos de ensino médio percebemos que ambos estão alinhados no sentindo de entender o papel do inglês como língua internacional no atual cenário contemporâneo. Então, parece haver uma divergência entre o clamor popular e a política linguística brasileira atual no tocante ao ensino desse idioma.

\section{Conclusão}

Este estudo teve como objetivo refletir sobre o ensino e a aprendizagem de inglês no Brasil contemporâneo. Para tanto, o estudo revisou políticas linguísticas e políticas de internacionalização, sugerindo que há uma tensão entre o papel formador e o instrumental do ensino da língua inglesa no Brasil, bem como uma falta de política em geral no tocante ao ensino de inglês como língua internacional e à internacionalização do Brasil.

A fim de subsidiar a reflexão proposta, o estudo analisou dados de um questionário com perguntas relacionadas ao ensino e à aprendizagem de línguas estrangeiras no Brasil respondido por 65 participantes. A análise sugere que brasileiros querem aprender inglês por sua função de língua internacional, e que a maior diferença entre o ensino desse idioma no Brasil está nos seus objetivos ora formador (na educação básica) ora instrumental (nos cursos livres e nos programas de internacionalização), confirmando a hipótese levantada na análise das políticas linguísticas. $\mathrm{O}$ artigo conclui que há uma tensão entre o papel formador e o instrumental do inglês, este último não contemplado por políticas linguísticas e de internacionalização. 


\section{Referências}

CANAGARAJAH, Suresh. Navigating language politics: a story of critical praxis. In: NICOLAIDES, Christine; et al. (Org.) Política e políticas linguísticas. Campinas: Pontes Editores, 2013. p. 43-62.

DORNYEI, Zoltán. Research methods in applied linguistics: quantitative, qualitative and mixed methodologies. Oxford: Oxford University Press, 2007.

FINARDI, Kyria R.; PREBIANCA, Gicele ; MOMM, Christine F. Tecnologia na educação: o caso da internet e do inglês como linguagens de inclusão. Cadernos do IL, v. 46, p. 193-208, 2013.

FINARDI, Kyria R.; FERRARI, Luciana. Reflecting on the English(es) taught in Brazil. Crop, v. 13, p. 205-214, 2008.

FINARDI, Kyria; ORTIZ, Ramon A. Globalization, internationalization and education: what is the connection? In: INTERNATIONAL CONFERENCE ON EDUCATION AND SOCIAL SCIENCES, 2014, Istambul. Proceedings... Istambul: Ocerint, v. 1, p. 45-53, 2014.

GIMENEZ, Telma. A ausência de políticas para o ensino da língua inglesa nos anos iniciais de escolarização no Brasil. In: NICOLAIDES, Christine; et al. (Org.) Política e políticas linguísticas. Campinas: Pontes Editores, 2013. p. 199-218.

GRADDOL, David. English next: why global English may mean the end of "English as a foreign language". The English Company (UK) Ltd.; British Council. 2006. Disponível em 
$<$ http://www.britishcouncil.org/learning-research-englishnext.pdf.>. Acesso em: 4 nov. 2015.

LAGARES, Xoán. C. Ensino do espanhol no Brasil: uma (complexa) questão de política linguística. In: NICOLAIDES, Christine; et al. (Org.) Política e políticas linguísticas. Campinas: Pontes Editores, 2013. p. 181-198.

LEFFA, Vilson. Prefácio. In: NICOLAIDES, Christine; et al. (Org.) Política e políticas linguísticas. Campinas: Pontes Editores, 2013. p. 7-10.

MACIEL, Ruberval. F. Políticas linguísticas, conhecimento local e formação de professores de línguas. In: NICOLAIDES, Christine; et al. (Org.) Política e políticas linguísticas. Campinas: Pontes Editores, 2013. p. 237-262.

MONTE MÓR, Walkyria. As políticas de ensino de línguas e o projeto de letramentos. In: NICOLAIDES, Christine; et al. (Org.) Política e políticas linguísticas. Campinas: Pontes Editores, 2013. p. 219-236.

NICOLAIDES, Christine. S.; TILIO, Rogério. C. Políticas de ensino e aprendizagem de línguas adicionais no contexto brasileiro: o caminho trilhado pela Alab. In: NICOLAIDES, Christine; et al. (Org.) Política e políticas linguísticas. Campinas: Pontes Editores, 2013. p. 285-306.

NICOLAIDES, Christine; et al. (Org.) Política e políticas linguísticas. Campinas: Pontes Editores, 2013.

PERUZZO, Sabrina. Crenças sobre o ensino de inglês $e$ pomerano como línguas estrangeiras no município de Santa Maria de Jetibá - ES. 2014. 34 p. Trabalho de Conclusão de 
Curso não publicado. Curso de Licenciatura em Letras Inglês. Universidade Federal do Espírito Santo, Vitória, 2014.

RAJAGOPALAN, Kanavillil. Política linguística: do que é que se trata, afinal? In: NICOLAIDES, Christine; et al. (Org.) Política e políticas linguísticas. Campinas: Pontes Editores, 2013. p. 19-142.

RAJAGOPALAN, Kanavillil. O ensino de línguas estrangeiras como uma questão política. In: MOTA, K.; SCHEYERL, D. (Org.). Espaços linguísticos: resistências e expansões. Salvador: EDUFBA, 2006. p. 15-24.

ROJO, Roxane. Caminhos para a LA: política linguística, política e globalização. In: NICOLAIDES, Christine; et al. (Org.) Política e políticas linguísticas. Campinas: Pontes Editores, 2013. p. 63-78.

\section{APÊNDICE 1 - QUESTIONÁRIO ESTUDANTES ENSINO MÉDIO}

1. Qual idioma estrangeiro você gostaria ou acha que deveria aprender? Numere de 1 a 5 , sendo que 1 tem maior importância e 2, menos importância.

( ) ESPANHOL

( ) INGLÊS

( ) FRANCÊS

( ) CHINÊS

( ) POMERANO

2. Caso você pudesse escolher apenas um idioma estrangeiro, qual seria? Por quê?

3. Sua família fala outro idioma? Qual? 


\section{APÊNDICE 2 - QUESTIONÁRIO PROFESSORES DE INGLÊS}

1) Por que ensinar inglês (e não outra língua estrangeira) no Brasil?

2) Que tipo de inglês devemos ensinar?

3) Que tipo de habilidade ensinar?

4) Há diferença entre o ensino de inglês público e privado?

5) Como deveríamos ensinar inglês no Brasil?

Submetido em: 24/10/2014 Aceito em: 20/06/2015

Title: The role of English in the formation and internationalization of education in Brazil 